\title{
A Study on the Activity of $\beta$-Glucuronidase in Bile in Connection with Precipitation of Calcium Bilirubinate
}

\author{
By \\ Tetsuo Maki, Tomonobu Sato and Takeo Sato \\ Prof. T. Maki's Surgical Clinic, Tohoku University, Sendai
}

(Received for publication, March 5, 1962)

\section{INTRODUCTION}

The present authors have been engaged in a series of studies on the problem why the pigmented calcium stones are so prevalent among the Japanese. Talseo Sato $^{1,2)}$, one of the authors, has previously reported in his chemical study of pigmented calcium stones that free bilirubin extractable with chloroform occupies $20-40 \%$ of the total weight of such gall stones, and that this free bilirubin exists in the gall stones in the form of inorganic salts nearly insoluble in water, chiefly calcium bilirubinate. There have been, however, no report answering the question of what is the exact process by which bilirubin in the bile comes into combination with calcium.

In the autumn of 1959, when Maki, another one of the authors, visited the chemist and physiologist Jesse L. Bollman at Mayo Clinic, he had a hint from the latter suggesting that enzyme in bile, namely, $\beta$-glucuronidase ( $\beta$-G hereunder), may play a part in the process of precipitation of calcium bilirubinate. This enzyme was first isolated in 1934 from bovine kidney, etc. by the late Prof. Masamune $^{3)}$ of Tohoku University during his series of researches on carbohydrates and has been studied by Oshima for determining the method of refining it and for the conditions of its reactions. ${ }^{4,5)}$ On the other hand, Billing and Lathe, ${ }^{6)}$ Schmid" and Talafant" separately found that the bilirubin sensitive to Van den Bergh's direct reaction is bilirubin glucuronide formed in vivo by combination of bilirubin with glucuronic acid, and Arias and London' ${ }^{\text {') }}$ remarked that this bilirubin glucuronide is formed by transfer of glucuronic acid from uridine diphosphate glucuronic acid (UDPGA) to free bilirubin hy the agency of the glucuronyl transferase.

Levvy ${ }^{10)}$ also admit that menthyl glucuronide can be hydrolysed by $\beta$-G, and Schmid ${ }^{11)}$ actually released glucuronic acid from bilirubin glucuronide (in the form

植 哲夫，佐藤智信，佐藤丈夫 
of azopigment) by hydrolysis using $\beta$-G. Thus, it is certain that $\beta$-G is an enzyme hydrolysing glucuronides, but there is no report on measurement of the activity of this enzyme in bile; accordingly, we have not heard of any work concerning the relationship between the activity of this enzyme and the process of precipitation of calcium biliruhinate in bile. Then the present authors took up the study to clarify whether the activity of $\beta$-G can be proved actually in bile or not, and the following results were obtained.

\section{EXPERIMENTAL MATERIALS AND METHOD}

As materials, bile was sampled from the gall bladder aseptically by direct puncture at laparotomy of patients of biliary tract diseases, mainly of cholelithiasis. Bile was similarly sampled from patients of other disease as control material. The sampled bile was immediately put in an ice-box for preservation and used for the experiment as early as possible.

First, we tried the original Fishman method ${ }^{12}$ (1948) for measurement of $\beta$ $\mathrm{G}$ in these bile samples, but failed in the attempt, unlike in the case with serum and urine. But Takeo Sato succeeded in modifying the method to adopt it to experiment with bile. ${ }^{13)}$ His method is schematized in Table I. The outstanding points of modification are as follows. First, the incubating time was prolonged

\section{Table I}

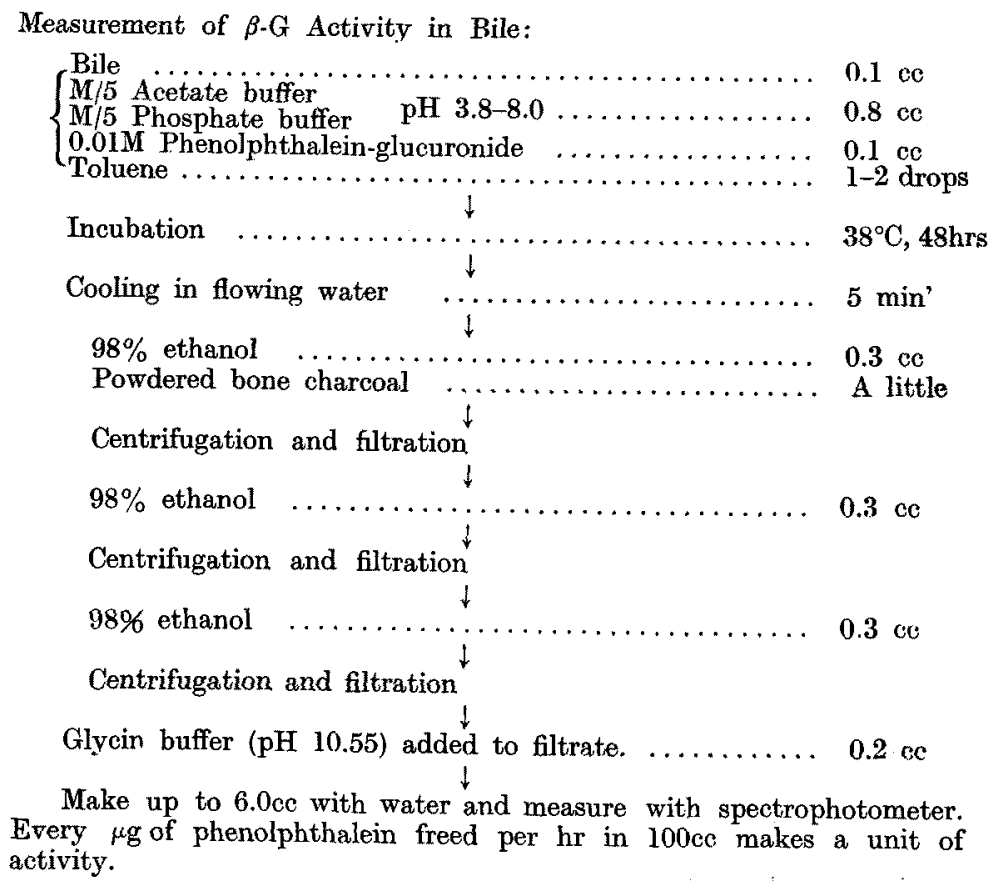


to $48 \mathrm{hrs}$ at $38^{\circ} \mathrm{C}$ and $98 \%$ ethanol was used instead of acetic acid trichloride for washing, to facilitate extraction of phenolphthalein. So, the liberated phenolphthalein was prevented from remaining as residue and the error at cholorimetry was minimized. Next, be diluted the bile sample and treated it with a small amount of powdered bone charcoal, to eliminate interference by bile pigment at colorimetry.

\section{EXPERIMENTAL RESULTS}

1. Results with Control Specimens.

Fishman et al. ${ }^{14)}$ found the activity of $\beta$-G heightened in various malignant tumor tissues and Masuya et $\left.a l .{ }^{15}\right)$ remarked the $\beta$-G activity in serum from cancer patients is higher than normal. In our study, however, the activity of $\beta$-G in bile from cancer patients was not different from the cases without malignant neoplasm. Then, we sampled control specimens at laparotomy from patients only excluding cases of liver and biliary tract diseases, namely, from 3 cases of gastric ulcer, 5 cases of visceroptosis and 4 cases of gastric cancer, or 12 cases in total, and determined the $\beta$-G activity in them. As shown in Fig. 1, no activity of the $\beta$-G was found in any case. The $\mathrm{pH}$ value in the incubation system was

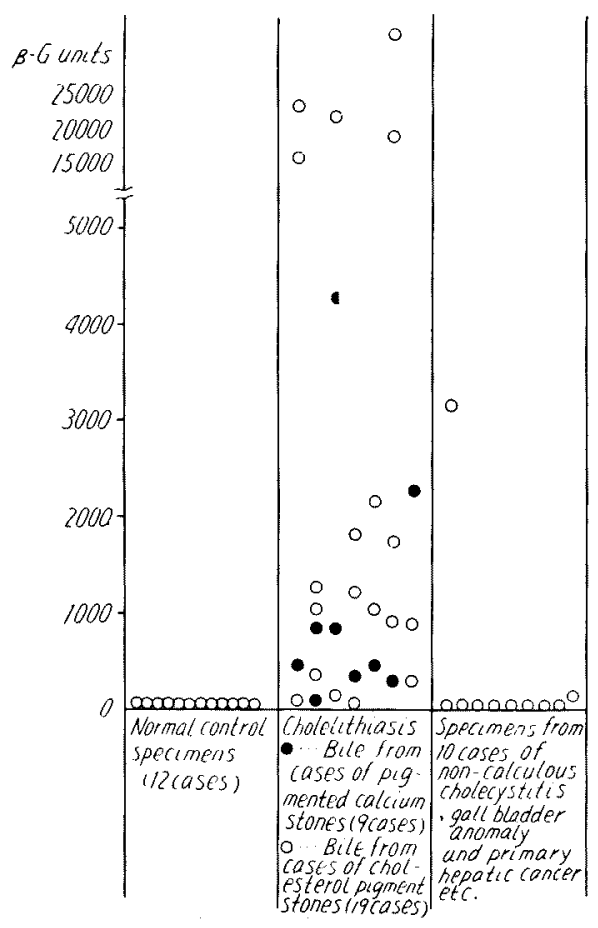

Fig .1. $\quad \beta$-G Activity in bile ( $\mathrm{pH} 4.5)$ 
kept at 4.5 throughout and the test culture proved that the specimens of bladder bile were free of bacteria.

2. Results with Specimens from Biliary Tract Disease Cases.

The specimens were sampled from the gall bladder of 9 cases of pigmented calcium stones and 19 cases of cholesterol stones, or 28 cases in total (Fig. 1). In the former the $\beta$-G activity ranged between trace and 4,250 units, averaging 1,107 units, showing a high level never observed in normal specimens. Upon culture tests, E. coli was always found in them.

In the specimens from cholesterol stone cases, the $\beta$-G activity registered $0-32,656$ units, averaging 6,604 units. Thus, there were some cases where the activity was as negative as in normal controls, and some again where the activity was on an exceedingly high level. The cause of such wide disparity will be discussed in a later paragraph. Test culture could prove scarcely any bacteria in these specimens.

In the specimens of gall bladder bile from ten patients of non-calculous diseases, such as non-calculous cholecystitis, gall bladder anomaly only 2 showed heightened $\beta$-G activity, as shown in Fig. 1. In these experiments also, the $\mathrm{pH}$ value in the incubation system was lept at 4.5 , conforming with the optimum $\mathrm{pH}$ value for the so-called visceral $\beta$-( $\frac{\gamma}{4}$. But since it is highly improbable that the $\mathrm{pH}$ value of bile in vivo should ever come down to 4.5, we cannot suppose that the

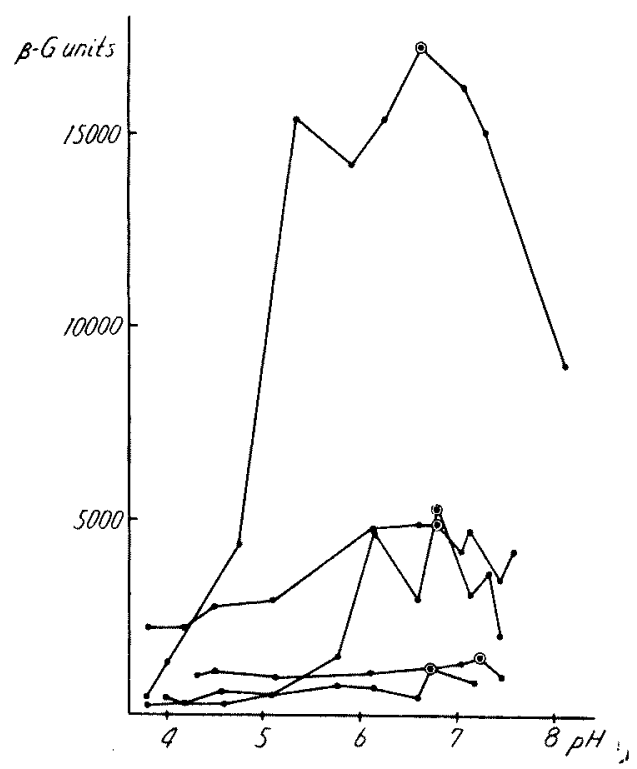

Fig. 2. $\quad \beta$-G Aetivity curves of bile specimens (from pigmented calcium stone cases) 
visceral $\beta-G$ should show the activity level in vivo as that registered in vitro.

As the $\mathrm{pH}$ value of normal bile generally ranges around 7 , the $\beta$-G activity of the same bile specimens was pursued while changing the $\mathrm{pH}$ value of the incubation system was gradually changed from 3.8-8.1. It was found that the activity showed the highest peak at the $\mathrm{pH}$ value of $6.6-7.15$ in the specimens from pigmented calcium stone cases as shown in Fig. 2, and at 4.5-5.2 in the specimens from cholesterol stone cases (Fig. 3). That is to say, in the bile infected with $\mathrm{E}$. coli from pigmented calcium stone cases, the $\beta$-G activity runs high around the optimum $\mathrm{pH}$ value for bacterial $\beta$-G, while in the aseptic bile from cholesterol stone cases, the activity rose in range of $\mathrm{pH}$ near the optimum value for visceral $\beta$-G.

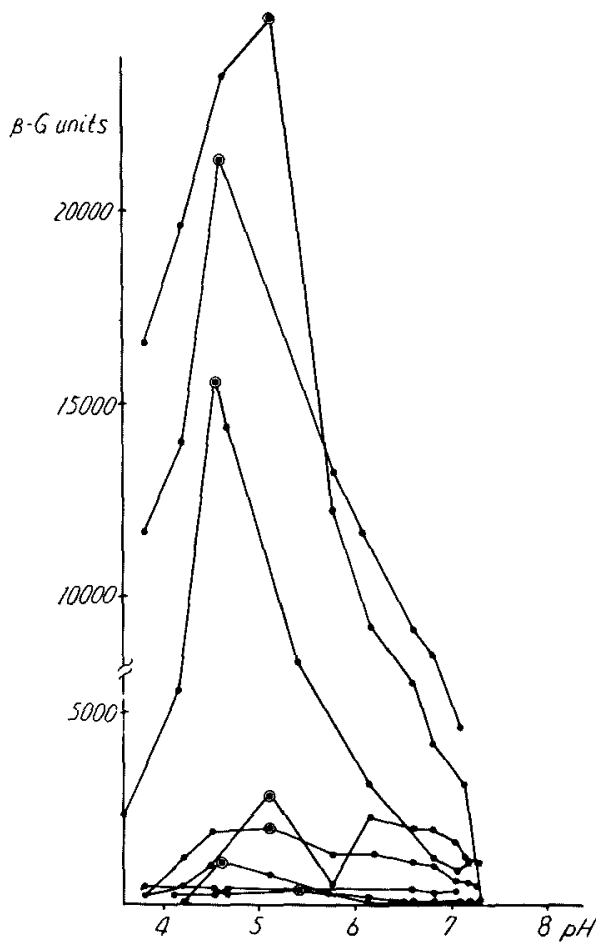

Fig. 3. $\beta$-G Activity curves of bile specimens (from cholesterol stone cases)

\section{SUMMARY AND DISCUSSION}

Upon measurement by our modified Fishman's method, we found that while the $\beta$-G activity was negative in bile from controls, it was obviously risen in bile from cholelithiasis patients. We can only make tentative inferences on the cause of such rise of $\beta$-G activity, the nearest being that the enzyme is inherently present 
also in normal bile, but its activity is inhibited by some factor.

As factors affecting the activity of enzymes in general, we can enumerate a number of external factors, such as environmental temperature, concentration of the substrate, $\mathrm{pH}$ value, content of co-enzymes, quantity of reaction product, quantity of reaction inhibiting substance, oxidation-reduction potential, ion density, etc. Accordingly, there may be many inferable factors inhibiting the $\beta$-G activity in bile, but it is a future problem for us to identify what the inhibiting factor is in this case, and from the results of our present experiments, we can only assume that the enzyme in normal bile is in a state of equilibrium in its reaction system due to the presence of such inhibiting factors. On the other hand, the high $\beta$-G activity in aseptic bile sampled from patients with cholesterol stones may be due to the weakening of some inhibitor and the consequent loss of the established equilibrium. Activity of $\beta$-G was also perceptible in the bile containing E. coli, whether from pigmented calcium stone cases or not, and here the bacterial $\beta$-G reported by Buehler et al. ${ }^{16)}$ in 1949 comes into the question. They found that the enzyme isolated from $\mathrm{E}$. coli and some other bacteria acted in hydrolysing steroid glucurnnides in urine like visceral $\beta$-G proper. More recently, Wakabayashi and Fishman ${ }^{17}$ pointed out that the bacterial $\beta$-G has a strong effect of hydrolysing steroid glucuronides when the $\mathrm{pH}$ is at the value of $5.5-7.0$ which is higher than the optimum value for visceral $\beta$-G. As noted above, the present authors also have found the activity of $\beta$-G in aseptic bile rising to the

Table II
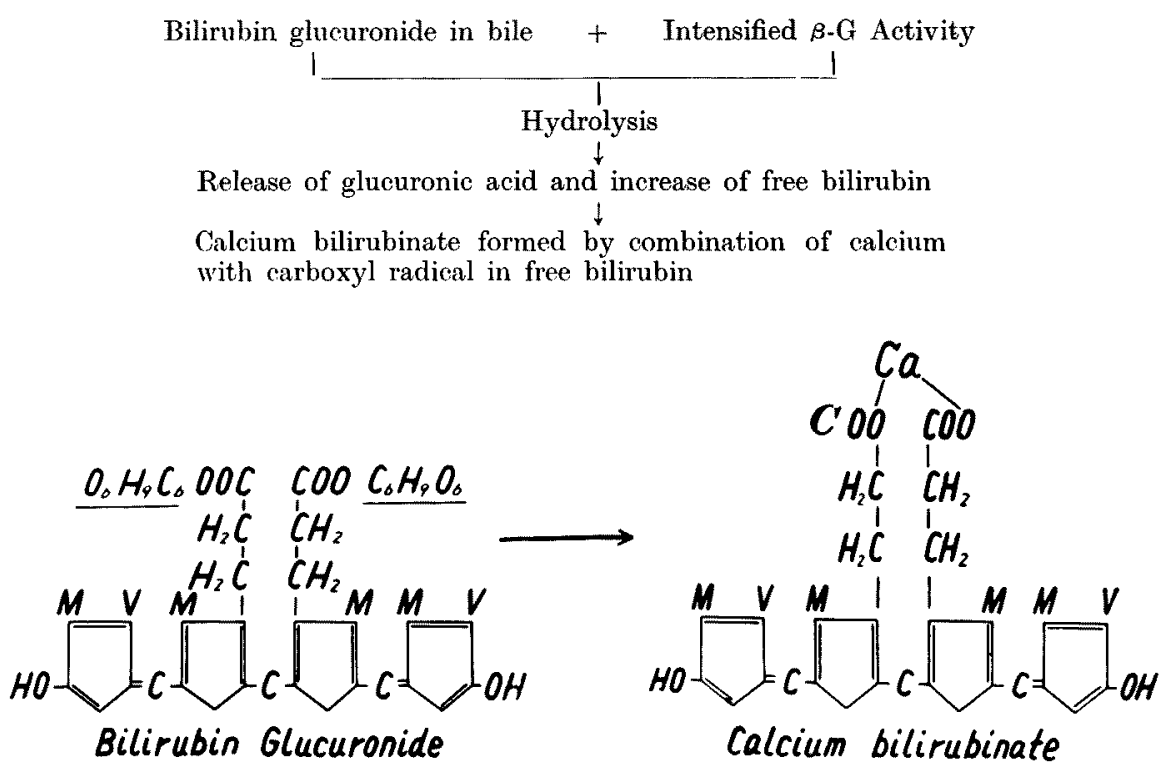
highest at $\mathrm{pH} 4.5-5.2$, but that in $\mathrm{E}$. coli containing bile was highest at $\mathrm{pH} 6.6-$ 7.15 , and we may infer that the $\beta$-G capable of showing ready rise of activity in vivo must be bacterial $\beta$-G derived from $\mathrm{E}$. coli, considering the $\mathrm{pH}$ value prevailing in bile in vivo. We are now still engaged in close researches on such bacterial $\beta-\mathrm{G}$, but it may be inferred that when the activity of $\beta$-G, a hydrolase of bilirubin glucuronide, is strengthened in bile, glucuronic acid combined with carboxyl radical of bilirubin will be released and be replaced by calcium as shown in Table II.

The confirmation of this hypothesis still requires studies from many angles, but at least theoretically we may conclude that the activity of $\beta$-G in bile plays an important post in combination of bilirubin and calcium in bile.

\section{CONCLUSION}

1. The present authors succeeded in measurement the hitherto unreported activity of $\beta$-glucuronidase $(\beta-\mathrm{G})$ in bile sampled from patients of biliary tract disease, using a modified Fishman's original method.

2. The $\beta$-G activity was negative in bile from control cases without biliary tract diseases, but was found perceptibly intensified in the bile specimens sampled from the gall bladder of nearly all patients of cholelithiasis, either of pigmented calcium stone or cholesterol stone type.

3. When the $\mathrm{pH}$ value in the incubation system was gradually raised from 3.8 to 8.1 , the activity of $\beta$-G in bile containing $E$. coli sampled from pigmented calcium stone cases or non-calculous cases rose to the highest level near the optimum $\mathrm{pH}$ for bacterial $\beta$-G $(6.6-7.15)$, while that in the aseptic bile specimens from cholesterol stone cases attained the maximum near the optimum $\mathrm{pH}$ for visceral $\beta$-G $(4.5-5.2)$.

4. Such observations on the optimum $\mathrm{pH}$ value for the activity of $\beta$-G led to the inference that the activity is chiefly that of the so-called bacterial $\beta$-G in the bacteria-containing bile from pigmented caliculi and that of the so-called visceral $\beta-G$ in the aseptic bile from the cholesterol stone cases.

5. When the activity of $\beta-\mathrm{G}$, a hydrolase acting on glucuronides in bile, is once accentuated, under certain conditions the bilirubin glucuronide will be hydrolysed into free bilimbin and glucuronic acid, and theoretically it may be inferred that the carboxyl radical in this free bilirubin is replaced by calcium. thus leading to formation of calcium bilirubinate.

\section{Acknowledgements}

In conclusion, we have to express our hearty thanks to Dr. J. L. Bollman and Dr. W. Walters, Mayo Clinic, Rochester, Minn., U.S.A., who gave us valuable suggestion on this problem. 


\section{References}

1) Sato, T., Hirosaki med. J. (Jap.), 1961, 12, 707.

2) Sato, T., Tohoku J. Exper. Med., 1962, 77, 83.

3) Masamune, H., J. Biochem. (Tokyo), 1934, 19, 353.

4) Oshima, G., J. Biochem. (Tokvo), 1934, 20, 361.

5) Oshima, G., J. Biochem. (Tokyo), 1936, 23, 305.

6) Billing, B.H. \& Lathe, G.H., Biochem. J., 1956, 63, 6P.

7) Schmid, R., Schweiz. med. Wschr., 1956, 86, 775.

8) T'alafant, E., Nature (Lond.), 1956, 178, 312.

9) Arias, I.M., \& London, I.M., Science, 1957, 126, 563.

10) Levvy, G.A., Biochem. J., 1948, 42, 2.

11) Schmid, R., Science, 1956, 124, 76.

12) Fishman W.H., Springer B. \& Brunetti, R., J. Biol. Chem., 1948, 173, 449.

13) Sato, T., Tohoku J. Exper. Med., 1962, 77, 23.

14) Fishman, W.H., Science, 1947, 105, 646.

15) Masuya T., Nobunaga, M. \& Kato, K., Saishin-Igaku (Jap.), 1961, 16, 70.

16) Buehler, H.J. Katzman P.A., Doisy, P.P. \& Doisy, E.A., Proc. Soc. Exper. Biol. Med., 1949, 72, 297.

17) Wakabayashi, M. \& Fishman, W.H., J. Biol. Chem., 1961, 236, 996. 